outcome, because the extent to which the patient's attitude can determine his own outcome needs bringing forward more emphatically.

However, their research requires to be put into perspective. They start their presentation with a quotation from Hooley \& Teasdale (1989) that "it is surprising that no study has sought to obtain data directly from patients themselves concerning their perceptions of criticism from family members" (p. 230). They also continue in their paper to say that "Patients' perceptions of their key relatives have only recently been studied, and it now appears that they may also have prognostic significance".

This in fact is not correct. Since the 1970s Scott and his co-workers have published a number of reports on their research into specific factors in the dyadic and triadic relation between schizophrenic patients and their parents which relate to outcome (Scott \& Casson, 1970; Scott, 1973; Scott \& Alwyn, 1978; Scott et al, Journal, July 1993, 163, 62-68). They used the Family Interpersonal Perception Test (FIPT), a self-rating questionnaire containing terms ranging from the very negative and critical (such as emotionally inadequate, interfering), to the very positive (such as secure, self-confident). The FIPT is scored by the patient and parents at the same session. They score how they see themselves, how they see each other, and how they expect to be seen by each of the others. From the scoring, factors were identified which have a well defined relation to outcome.

It is interesting that the essential findings from the research of Scott $e t$ al and Lebell $e t$ al have much in common. In both a poor outcome is associated with the patient expecting a negative view from their relative(s), and with the relative(s) taking a negative view of the patient. In both there is a correlation between how the relative sees the patient and how the patient thinks he/she is seen (indicating that the patient has an accurate awareness of the relation), although in Scott $e$ t als studies this is so only for poor-outcome patients. Thus both groups of researchers give the patient a key role in influencing his/her own outcome, with the patient's scoring predicting it better than that of his/her parents (Scott et al, Journal, July $1993,163,62-68$ ).

Hooley, J. M. \& Teasdale, J. D. (1989) Predictors of relapse in unipolar depressives: expressed emotion, martial distress, and perceived criticism. Journal of Abnormal Psychology, 94, 229-235.

Scort, R. D. (1973) The treatment barrier; part 2. The patient as an unrecognised agent. British Journal of Medical Psychology, 46, 57-67.

- \& CASSON, P. D. (1970) Violation of parental role structure and outcome in schizophrenia. A scored analysis of the parentpatient relationship. Social Science and Medicine, 4, 41-64.
- \& ALWYN, S. (1978) Patient-parent relationships and the course and outcome of schizophrenia. British Journal of Medical Psychology, 51, 343-355.

257 Alexandra Road

DENNIS SCOTT

Muswell Hill

London N10 2EU

Claybury Hospital

Woodford Bridge

Essex IG8 8BY

LEONARD FAGIN

\section{Down's syndrome, dementia, and superoxide dismutase}

SIR: Drs Dickinson \& Singh (Journal, June 1993, 162 , 811-817) discuss the possible relationship between cognitive decline and raised mean cell volume (MCV) in people with Down's syndrome (DS). We recently investigated 92 people with DS (Mean age 44.2 years, range 19-72, s.d. 12.3) for an ICD-10 psychiatric diagnosis for dementia in Alzheimer's disease with early onset and for a diagnosis of a depressive episode. All cases were investigated for raised MCV (>98 fl, normal range 80-98 f).

For an association between raised $\mathrm{MCV}$ and clinical dementia to be valid, the changes in MCV must be due to increasing age per se. For our sample, no statistically significant association was found for these two parameters (Pearson's coefficient $\mathbf{0} 0.448$ ).

Twenty-two subjects (mean age 54.0 years, range $42-72$, s.d. 8.09) fulfilled ICD-10 criteria for dementia. A statistically significant association, using $\chi^{2}$ tests, between the diagnosis of clinical dementia and a raised MCV was found $(P=0.01)$. Two patients fulfilled ICD-10 criteria for depression, but neither had raised $\mathrm{MCV}$ values.

We support previous findings (Lansdall Welfare \& Hewitt, Journal, April 1986, 148, 482-483) of an association between intellectual deterioration in people with DS and macrocytosis, and tentatively rule out that changes in MCV are secondary to mental illness per se.

University of Birmingham

V. P. Prasher M. Cheung Chung

Queen Elizabeth Psychiatric Hospital

Mindelsohn Way

Birmingham B15 2QZ

\section{Home-based acute psychiatric services}

SIR: I read with interest the two papers by Burns et al (Journal, July 1993, 163, 49-54, 55-61) on a controlled trial of home-based acute psychiatric services. 